\title{
Bacillus thuringiensis Toxins: Functional Characterization and Mechanism of Action
}

\author{
Yolanda Bel ${ }^{1,2, *(\mathbb{D})}$, Juan Ferré ${ }^{1,2, *(\mathbb{D})}$ and Patricia Hernández-Martínez ${ }^{1,2, *(\mathbb{D})}$ \\ 1 Instituto de Biotecnología y Biomedicina (BIOTECMED), Universitat de València, 46100 Burjassot, Spain \\ 2 Department of Genetics, Universitat de València, 46100 Burjassot, Spain \\ * Correspondence: yolanda.bel@uv.es (Y.B.); juan.ferre@uv.es (J.F.); patricia.hernandez@uv.es (P.H.-M.)
}

Received: 30 November 2020; Accepted: 8 December 2020; Published: 10 December 2020

Bacillus thuringiensis (Bt)-based products are the most successful microbial insecticides to date. This entomopathogenic bacterium produces different kinds of proteins whose specific toxicity has been shown against a wide range of insect orders, nematodes, mites, protozoa, and human cancer cells. Some of these proteins are accumulated in parasporal crystals during the sporulation phase (Cry and Cyt proteins), whereas other proteins are secreted in the vegetative phase of growth (Vip and Sip toxins). Currently, insecticidal proteins belonging to different groups (Cry and Vip3 proteins) are widely used to control insect pests and vectors both in formulated sprays and in transgenic crops (the so-called Bt crops). Despite the extensive use of these proteins in insect pest control, especially Cry and Vip3, their mode of action is not completely understood.

The aim of this Special Issue was to gather information that could summarize (in the form of review papers) or expand (research papers) the knowledge of the structure and function of Bt proteins, as well as shed light on their mode of action, especially regarding the insect receptors. This subject has generated great interest, and this interest has been materialized into the 18 papers published in this issue.

This Special Issue, "Bacillus thuringiensis Toxins: Functional Characterization and Mechanism of Action", includes five review papers and 13 research papers. The review papers bring up to date important aspects of Bt pathogenicity, such as its interaction with the intestinal microbiota and the immune system of the insect [1]. The current knowledge about Vip proteins has also been reviewed [2], as has the contribution that the use of toxin mutants has made to the knowledge of the mode of action of the three-domain Cry proteins [3]. On the other hand, two more review papers recapitulate the information on the cytocidal activity of Bt proteins [4] or the insecticidal activity of Bt proteins against coleopteran pests [5]. All these review papers are of high value, allowing readers to stay updated on the different aspects of the Bt field described here.

The Special Issue also gathers information that could expand the knowledge of the structure and function of Bt proteins and sheds light on their mode of action, especially regarding the insect receptors. Publishing papers focusing on the steps that remain blurred within the mode of action of all Bt insecticidal proteins, including the three-domain Cry proteins, was one of the main goals. The role of receptors such as cadherin, $\mathrm{ABCC} 2$, and $\mathrm{ABCA} 2$ on the toxicity of Bt proteins in different lepidopterans has been investigated in three different papers [6-8]. In addition, other steps in the mode of action (that comprises protein solubilization, activation, binding, oligomerization, and pore formation) have also been addressed. Examples of these steps include the involvement of a novel trypsin protein for toxin activation in Plutella xylostella, discovered after studying a Cry1Ac resistant strain [9], and the promotion of oligomerization of the activated Cry1Ia with insect brush border midgut vesicles, in vitro [10]. The toxicity-promoting effect of a Bt chitin-binding protein that binds to the insect peritrophic matrix has also been studied [11]. Moreover, the Special Issue includes a paper highlighting the synergistic mosquitocidal activity of the parasporal Cry and Cyt proteins present in 
B. thuringiensis ser. israelensis [12], and it also includes a manuscript focused on deciphering the amino acid residues important for the interaction of Cyt2A protein with membrane lipids, a binding step necessary to exert its cytolytic action [13].

The vegetative insecticidal proteins (Vip3) secreted by Bacillus thuringiensis are nowadays considered as the new generation of insecticidal Bt toxins because of their different structural and molecular properties regarding the classical Bt 3-D Cry proteins. Vip3 toxins have been already introduced in Bt-crops to control lepidopteran pests. However, little is known about their mode of action. In the Special Issue, five papers analyze different aspects of its biology. They cover aspects ranging from its crystal structure [14] and structural-functional domain analyses [15] to different aspects in the mode of action, such as a study of a possible receptor (the alkaline phosphatase) in a resistant strain [16], the role of oligomerization in toxicity [17], and the study of intracellular events promoted by Vip3A intoxication in Spodoptera frugiperda Sf9 cells [18].

In summary, the Special Issue brings together papers of important scientific value in the field of Bt. The review and research papers included will help keep readers up to date on the topic and, at the same time, will contribute to increasing the vast knowledge of Bt and its insecticidal proteins. These studies will help to provide useful information for the development of new strategies to fight against pest insects, in the least aggressive and harmful but better environmental scenario.

Funding: This research received no external funding.

Acknowledgments: The editors are grateful to all of the authors who contributed to this Special Issue "Bacillus thuringiensis Toxins: Functional Characterization and Mechanism of Action". Special thanks to the peer reviewers for their expertise evaluations, which have contributed to increasing the quality of the research works and reviews compiled in this Special Issue. Finally, we thank the MDPI management team and staff for their valuable contributions, organization, and editorial support.

Conflicts of Interest: The authors declare no conflict of interest.

\section{References}

1. Li, S.; De Mandal, S.; Xu, X.; Jin, F. The Tripartite interaction of host immunity-Bacillus thuringiensis infection-gut microbiota. Toxins 2020, 12, 514. [CrossRef] [PubMed]

2. Syed, T.; Askari, M.; Meng, Z.; Li, Y.; Abid, M.A.; Wei, Y.; Guo, S.; Liang, C.; Zhang, R. Current insights on vegetative insecticidal proteins (Vip) as next generation pest killers. Toxins 2020, 12, 522. [CrossRef] [PubMed]

3. Vílchez, S. Making 3D-Cry toxin mutants: Much more than a tool of understanding toxins mechanism of action. Toxins 2020, 12, 600. [CrossRef] [PubMed]

4. Mendoza-Almanza, G.; Esparza-Ibarra, E.L.; Ayala-Luján, J.L.; Mercado-Reyes, M.; Godina-González, S.; Hernández-Barrales, M.; Olmos-Soto, J. The Cytocidal spectrum of Bacillus thuringiensis toxins: From insects to human cancer cells. Toxins 2020, 12, 301. [CrossRef]

5. Domínguez-Arrizabalaga, M.; Villanueva, M.; Escriche, B.; Ancín-Azpilicueta, C.; Caballero, P. Insecticidal activity of Bacillus thuringiensis proteins against Coleopteran pests. Toxins 2020, 12, 430. [CrossRef]

6. Zhang, J.; Jin, M.; Yang, Y.; Liu, L.; Yang, Y.; Gómez, I.; Bravo, A.; Soberón, M.; Xiao, Y.; Liu, K. The cadherin protein is not involved in susceptibility to Bacillus thuringiensis Cry1Ab or Cry1Fa toxins in Spodoptera frugiperda. Toxins 2020, 12, 375. [CrossRef] [PubMed]

7. Wang, X.; Xu, Y.; Huang, J.; Jin, W.; Yang, Y.; Wu, Y. CRISPR-mediated knockout of the $A B C C 2$ gene in Ostrinia furnacalis confers high-level resistance to the Bacillus thuringiensis Cry1Fa toxin. Toxins 2020, 12, 246. [CrossRef] [PubMed]

8. Li, X.; Miyamoto, K.; Takasu, Y.; Wada, S.; lizuka, T.; Adegawa, S.; Sato, R.; Watanabe, K. ATP-binding cassette subfamily a member 2 is a functional receptor for Bacillus thuringiensis Cry2A toxins in Bombyx mori, but not for Cry1A, Cry1C, Cry1D, Cry1F, or Cry9A toxins. Toxins 2020, 12, 104. [CrossRef] [PubMed]

9. Gong, L.; Kang, S.; Zhou, J.; Sun, D.; Guo, L.; Qin, J.; Zhu, L.; Bai, Y.; Ye, F.; Akami, M.; et al. Reduced expression of a novel midgut trypsin gene involved in protoxin activation correlates with Cry1Ac resistance in a laboratory-selected strain of Plutella xylostella (L.). Toxins 2020, 12, 76. [CrossRef] [PubMed] 
10. Khorramnejad, A.; Domínguez-Arrizabalaga, M.; Caballero, P.; Escriche, B.; Bel, Y. Study of the Bacillus thuringiensis Cry1Ia protein oligomerization promoted by midgut brush border membrane vesicles of lepidopteran and coleopteran insects, or cultured insect cells. Toxins 2020, 12, 133. [CrossRef] [PubMed]

11. Qin, J.; Tong, Z.; Zhan, Y.; Buisson, C.; Song, F.; He, K.; Nielsen-LeRoux, C.; Guo, S. A Bacillus thuringiensis chitin-binding protein is involved in insect peritrophic matrix adhesion and takes part in the infection process. Toxins 2020, 12, 252. [CrossRef] [PubMed]

12. Valtierra-de-Luis, D.; Villanueva, M.; Lai, L.; Williams, T.; Caballero, P. Potential of Cry10Aa and Cyt2Ba, Two minority $\delta$-endotoxins produced by Bacillus thuringiensis ser. israelensis, for the control of Aedes aegypti larvae. Toxins 2020, 12, 355. [CrossRef] [PubMed]

13. Tharad, S.; Promdonkoy, B.; Toca-Herrera, J.L. Protein-Lipid Interaction of Cytolytic Toxin Cyt2Aa2 on Model lipid bilayers of erythrocyte cell membrane. Toxins 2020, 12, 226. [CrossRef] [PubMed]

14. Jiang, K.; Zhang, Y.; Chen, Z.; Wu, D.; Cai, J.; Gao, X. Structural and Functional Insights into the C-terminal Fragment of insecticidal Vip3A toxin of Bacillus thuringiensis. Toxins 2020, 12, 438. [CrossRef] [PubMed]

15. Gomis-Cebolla, J.; Ferreira dos Santos, R.; Wang, Y.; Caballero, J.; Caballero, P.; He, K.; Jurat-Fuentes, J.L.; Ferré, J. Domain shuffling between Vip3Aa and Vip3Ca: Chimera stability and insecticidal activity against European, American, African, and Asian pests. Toxins 2020, 12, 99. [CrossRef] [PubMed]

16. Pinos, D.; Chakroun, M.; Millán-Leiva, A.; Jurat-Fuentes, J.L.; Wright, D.J.; Hernández-Martínez, P.; Ferré, J. Reduced membrane-bound alkaline phosphatase does not affect binding of Vip3Aa in a Heliothis virescens resistant colony. Toxins 2020, 12, 409. [CrossRef] [PubMed]

17. Shao, E.; Zhang, A.; Yan, Y.; Wang, Y.; Jia, X.; Sha, L.; Guan, X.; Wang, P.; Huang, Z. Oligomer formation and insecticidal activity of Bacillus thuringiensis Vip3Aa toxin. Toxins 2020, 12, 274. [CrossRef] [PubMed]

18. Hou, X.; Han, L.; An, B.; Zhang, Y.; Cao, Z.; Zhan, Y.; Cai, X.; Yan, B.; Cai, J. Mitochondria and lysosomes participate in Vip3Aa-induced Spodoptera frugiperda Sf9 cell apoptosis. Toxins 2020, 12, 116. [CrossRef] [PubMed]

Publisher's Note: MDPI stays neutral with regard to jurisdictional claims in published maps and institutional affiliations.

(C) 2020 by the authors. Licensee MDPI, Basel, Switzerland. This article is an open access article distributed under the terms and conditions of the Creative Commons Attribution (CC BY) license (http://creativecommons.org/licenses/by/4.0/). 